\title{
PDGFRB/MYO18A Fusion Gene
}

National Cancer Institute

\section{Source}

National Cancer Institute. PDGFRB/MYO18A Fusion Gene. NCI Thesaurus. Code C99681.

A fusion gene that results from a chromosomal translocation $t(5 ; 17)(q 33-34 ; q 11.2)$

which fuses exon 9 of the PDGFRB gene to exon 41 of the MYO18A gene. This

rearrangement is associated with eosinophilia associated with atypical myeloproliferative neoplasm. 